\title{
Great Volatility, Great Moderation and Great Moderation Again
}

\author{
Jakob Grazzini*a,c and Domenico Massaro ${ }^{\dagger \mathrm{b}, \mathrm{c}}$ \\ ${ }^{\mathrm{a}}$ Department of Economics and Management, University of Pavia, Italy. \\ ${ }^{\mathrm{b}}$ Department of Economics, Management and Quantitative Methods, University of Milan, Italy. \\ ${ }^{\mathrm{c}}$ Complexity Lab in Economics, Milan, Italy.
}

April 12, 2021

\begin{abstract}
We investigate the sources of changes in GDP volatility observed from 1966 to 2018. We develop a general equilibrium model and calibrate it to US data to characterize the contribution of micro level productivity shocks, inter-sectoral linkages and households' behavior to aggregate volatility. Our results show that changes in sectoral volatility played an important role in shaping GDP volatility and that asymmetries in the economy had a different impact on aggregate volatility over time. Moreover, we show that, despite an increase before the financial crisis of 2007, aggregate volatility has remained low until 2018.
\end{abstract}

JEL codes: E32, E23, D57.

Keywords: Business Cycle, Micro-Macro Volatility, Input-Output Network

${ }^{*}$ Email: jakob.grazzini@unipv.it. Address: Via San Felice 5, 27100 Pavia, Italy.

${ }^{\dagger}$ Email: domenico.massaro1@unimi.it. Address: Via Conservatorio 7, 20122 Milano, Italy. 


\section{Introduction}

GDP volatility in the US exhibited a high degree of time variation in the second part of the last century. The years ranging from 1960s to early-1980s were characterized by a surge in the volatility of GDP, which was then followed by a sharp decline which lasted until the mid-1990s (see e.g. McConnell and Perez-Quiros, 2000; Stock and Watson, 2002). We refer to these distinct periods respectively as "great volatility" and "great moderation". The "great moderation" led to a prolonged period of low volatility, temporarily interrupted during the global financial crisis (see Fig. 1). After the crisis, aggregate volatility decreased even further and the US economy went through a period of "great moderation (again)".

Traditional explanations of GDP fluctuations relied on economy-wide disturbances, such as aggregate productivity shocks (see e.g. Lucas, 1977). The origins of such aggregate shocks are, however, still a matter of debate. A significant branch of the literature, influenced by the work of Long and Plosser (1983) and Horvath (1998, 2000), advanced the hypothesis that fluctuations at the macro level may originate from micro level, e.g. sectoral, shocks. Dupor (1999) argues instead against the microeconomic origins of aggregate fluctuations on the basis of a diversification argument: in an economy with a large number of sectors, the aggregate effect of idiosyncratic sectoral shocks should decay at a rate proportional to the square root of the number of sectors. More recently, Gabaix (2011) pointed out that when firms' size is heterogeneous and distributed according to a Zipf law, aggregate fluctuations may emerge from shocks originated at the micro level: idiosyncratic shocks to a handful of very large firms do not wash out in the aggregate and decay at a much lower rate than predicted by the diversification argument. The work of Di Giovanni et al. (2014) provides empirical evidence for the importance of firm-specific shocks in explaining aggregate fluctuations. Moreover, Acemoglu et al. (2012) show that the diversification argument does not hold in the presence of asymmetric input-output linkages: production complementarities may lead to the amplification of sector-specific shocks and generate aggregate volatility.

Focusing on the origins of the large fall in GDP volatility associated with the "great moderation", several papers provided empirical evidence on the importance of sectoral sources in explaining aggregate fluctuations. Proposed explanations typically connect changes in aggregate volatility to either changes in the weights of different sectors in the economy or changes in the volatility within 
sectors. McConnell and Perez-Quiros (2000) relate the decline in GDP volatility occurred around 1984 to a decline in the volatility within the sector of durable goods. Carvalho and Gabaix (2013) link changes in aggregate volatility to changes in the structure of the economy described by the time variation of sectoral sales over GDP. Moro (2012) explains the "great moderation" by means of a structural change described by an increase in the size of the services sector (less intensive in intermediate inputs) relative to the manufacturing sector (more intensive in intermediate inputs). Moro (2012) also hypothesizes that the time variation of total factor productivity (TFP) at the sectoral level played an important role in shaping aggregate volatility in the first half the 2000s. ${ }^{1}$

In this paper we consider both a time-varying structure of sectoral weights in the economy and time-varying sectoral TFP volatility, and study how their interaction shaped GDP volatility. We frame our analysis in a model with $n$ sectors using capital, labor and intermediate goods to produce gross output along the lines of Long and Plosser (1983), Jones (2011) and Carvalho and Gabaix (2013). Our theoretical framework links the dynamics of GDP volatility to the following time-varying terms: $(i)$ the weights of each sector in the economy defined as "Domar weights", i.e. sectoral gross nominal output over GDP (Domar, 1961), (ii) sectoral TFP volatilities, (iii) a multiplying factor which depends on labor and capital supply decisions of households in the economy.

We calibrate the model to US data from 1960 to 2018 and perform a series of counterfactual exercises in order to isolate $(i)$ the impact of time-varying sectoral TFP volatilities on GDP volatility, (ii) the amplification of idiosyncratic sectoral productivity shocks due to the presence of production linkages, (iii) the role played by heterogeneity in the Domar weights. Such heterogeneity reflects asymmetries in the weights of different sectors in the production system. Using our calibrated model we are able to identify the causes of changes in aggregate volatility observed in the last 50 years.

Our main findings can be summarized as follows. First, sectoral TFP volatilities are an important driver of GDP volatility. As an example, we find that the evolution of aggregate volatility from

\footnotetext{
${ }^{1}$ Other explanations for the "great moderation" include better inventory management (Kahn et al., 2002), improvements in financial markets facilitating consumption and investment smoothing (Blanchard and Simon, 2001), changes in the volatility of aggregate shocks and impulse-response propagation mechanisms (Stock and Watson, 2002; Galí and Gambetti, 2009), decline in the variability of the shock specific to the investment account equilibrium condition (Justiniano and Primiceri, 2008), changes in the demographic composition of the workforce (Jaimovich and Siu, 2009), and better policy (Clarida et al., 2000) among others.
} 
1995 onwards has been essentially caused by changes in sectoral volatilities rather than changes in the structure of the production network. However, sectoral TFP volatilities alone are not able to fully describe the behavior of aggregate fluctuations. Second, the presence of an input-output network amplifies sectoral-level fluctuations. In fact, the higher the degree of overall intermediate input-intensity of production, the stronger the amplification effect. Third, the impact of heterogeneity in the Domar weights has greatly changed over time. In particular, from 1970 until mid-1980s and from early 2000s until mid-2010s, asymmetry in sectoral weights had an amplifying effect on volatility, with a rather strong impact around 1980. In the rest of the sample, the asymmetric structure of the production system had an almost neutral, or even dampening effect on aggregate volatility. These different impacts cannot be explained by different levels of asymmetry alone, but a major role is played by changes over time in the correlation between Domar weights and sectoral TFP volatilities. For example, our findings show that during the "great moderation" the level of asymmetry remained almost unchanged, while the correlation between Domar weights and TFP volatilities became more negative. Finally, we show that the dynamics of GDP volatility can be largely explained by the contribution of just a few sectors.

Our paper contributes to the literature on the microeconomic origins of aggregate fluctuations. It is most related to Carvalho and Gabaix (2013), who introduce a measure of "fundamental volatility", i.e. volatility derived only from sectoral shocks, and show that GDP volatility tracks fundamental volatility. In Carvalho and Gabaix (2013), the evolution of fundamental volatility only depends on sectoral weights changing over time, while sectoral TFP volatilities are constant. We build on their theoretical framework and introduce time-varying micro-level TFP volatilities. ${ }^{2}$ We decompose changes in fundamental volatility to measure the relative contributions of changes in sectoral TFP volatilities and in the Domar weights, finding that changes in idiosyncratic volatilities play a predominant role in explaining variations in fundamental volatility. In fact, we find that changes in Domar weights cannot account for movements in aggregate volatility observed between 1995 and 2018. Moreover, also during the period 1960s - 1990s, Domar weights can only partially account for observed changes in aggregate volatility. Furthermore, our results suggest that the

\footnotetext{
${ }^{2}$ Carvalho and Gabaix (2013) also consider a measure of time-varying sectoral volatilities estimated using a GARCH(1,1) model. They find that this measure does not improve the explanatory power of the model when compared to the case of constant sectoral volatilities. We use instead a non-parametric measure of time-varying sectoral volatilities in a different setup and show that it improves the explanatory power of the model. See Table C.1 in Online Appendix $\mathrm{C}$ for a comparison between these models.
} 
time-varying interaction between Domar weights and sectoral TFP volatilities is a key driver of aggregate volatility. Therefore, explanations of the volatility dynamics based only on changes of sectoral weights in the economy or only on changes in sectoral volatilities may overlook the important role played by the interaction between these two factors.

This paper also contributes to the debate on the alleged end of the "great moderation". A strand of the literature suggests that the financial crisis marked the end of the "great moderation" period (see e.g. Taylor, 2011; Stock and Watson, 2017). Other contributions do not find any structural break in volatility (see e.g. Gadea et al., 2018; Charles et al., 2018), suggesting instead that the peak in volatility observed during the crisis was an episode rather than a structural increase in GDP fluctuations. We contribute to this debate by showing that aggregate volatility indeed increased in the years before the crisis. This increase was relatively small compared to the "great volatility" period and mainly caused by an increase in TFP volatility of finance-related sectors. However, aggregate volatility sharply declined after the crisis, leading to a new period of very low volatility. This suggests that the financial crisis was an isolated episode in a period of generally low volatility.

The rest of the paper is organized as follows. In Section 2 we develop the theoretical model underpinning our empirical analysis. In Section 3 we discuss the data used for our analysis and the calibration of the model. In Section 4 we discuss the counterfactual analysis that will then be used in Section 5 to explain the history of US GDP volatility in the last 50 years. Section 6 concludes.

\section{$2 \quad$ Model}

In this section we present an analytically tractable model which will be the basis for our empirical analysis. A detailed derivation can be found in Online Appendix A.

There are $n$ sectors producing intermediate goods. Each intermediate good can be used as input for the production of intermediate goods or it can be aggregated into a single final consumption good. Households consume and supply labor. Each sector $i$ producing intermediate goods uses a Cobb-Douglas technology function given by

$$
Q_{i}=A_{i}\left(K_{i}^{\alpha_{i}} H_{i}^{\left(1-\alpha_{i}\right)}\right)^{\left(1-w_{i}\right)} \prod_{j=1}^{n} d_{i j}^{w_{i j}}
$$


where $A_{i}$ is an exogenous productivity term uncorrelated across sectors, $K_{i}$ and $H_{i}$ represent quantities of capital and labor respectively, while $d_{i j}$ represents the quantity of good $j$ used in the production of sector $i$. The production technology features constant returns to scale so that $0<\alpha_{i}<1$ and $\sum_{j} w_{i j}=w_{i}$.

Instead of specifying a utility function over the $n$ different goods, we follow Jones (2011) and specify a single final good given by a log-linear aggregation of the output of the $n$ sectors

$$
Y=\prod_{i=1}^{n} c_{i}^{\beta_{i}},
$$

where $Y$ denotes the quantity of the final good, $c_{i}$ is the quantity of each intermediate good used to produce the final good and $\sum_{i=1}^{n} \beta_{i}=1$. We set the price of the final good $P=1$ so that $Y$ denotes both real and nominal aggregate good.

Households in the economy are all equal, and can therefore be represented by a representative household with utility function $u(C, H)=C-H^{1+\frac{1}{\phi}}$, where $C$ is consumption, $H$ is supplied labor and $\phi>0$ is the Frisch elasticity of labor supply. The competitive equilibrium is the result of the planner's problem, which is to maximize the household's utility subject to the resources constraint:

$$
\begin{aligned}
& \max u(C, H)=C-H^{1+\frac{1}{\phi}} \\
& \text { s.t. } C=Y-\kappa K^{\varphi}
\end{aligned}
$$

where $\kappa K^{\varphi}$ represents a non-linear capital adjustment cost. As shown in Online Appendix A, the aggregate good production, or GDP level, in the competitive equilibrium is given by

$$
\log (Y)=m \gamma^{\prime} \varepsilon+\Psi
$$

Eq. (4) describes (log-)GDP as a weighted sum of sectoral total factor productivities, collected in vector $\varepsilon=\left(\log \left(A_{1}\right), \ldots, \log \left(A_{n}\right)\right)^{\prime}$, where the weights contained in vector $\gamma$ are known in the literature as Domar weights (Domar, 1961). The scalar $m$ is a multiplying factor described below, while the constant $\Psi$ is a convolution of structural parameters which only influences the level of economic activity. Since we are interested in studying only the impact of productivity shocks on GDP, we leave the detailed description $\Psi$ to Online Appendix A and focus below on the Domar 
weights $\gamma$ and on the multiplying factor $m$.

The Domar weights are defined as $\gamma^{\prime} \equiv \beta^{\prime}(I-W)^{-1}$. The vector $\beta^{\prime}=\left(\beta_{1}, \ldots, \beta_{n}\right)$ contains the exponents, or shares of intermediate goods, in final good production, while matrix $W$ collecting the exponents $w_{i j}$ is the input-output matrix of intermediate goods shares. Matrix $\bar{W}=(I-W)^{-1}$ is the Leontief inverse matrix, whose $i j$-th element describes how much an increase in productivity in sector $j$ raises output in sector $i$ taking into account all direct and indirect effects in the production structure. Multiplying the vector $\beta$ by the $j$-th column of matrix $\bar{W}$ yields $\gamma_{j}=\sum_{i=1}^{n} \beta_{i} \bar{w}_{i j}$. Therefore, the $j$-th element of $\gamma^{\prime}$ sums the effects of sector $j$ on all the other sectors of the economy, weighted by their shares in final good production. In other words, the Domar weights measure the impact of a change in productivity in a certain sector on final good production, i.e. on aggregate GDP. Heterogeneity in sectoral Domar weights thus reflects $i$ ) heterogeneity in the shares of intermediate goods in final production, i.e. in the elements of vector $\beta$, ii) asymmetry in sectoral importances as intermediate input suppliers in the production network.

The multiplying factor is defined as $m \equiv(1-\Gamma)^{-1}$, where the scalar $\Gamma$ is given by

$$
\Gamma \equiv \gamma^{\prime}\left(\frac{1}{\varphi} k_{s}+\frac{\phi}{1+\phi} h_{s}\right)
$$

The vector $k_{s}$ contains the production elasticities $\left(1-w_{i}\right) \alpha_{i}$ for capital, while the vector $h_{s}$ contains the production elasticities $\left(1-w_{i}\right)\left(1-\alpha_{i}\right)$ for labor.

In this paper we are interested in the impact that changes in sectoral TFPs, denoted as $\Delta \varepsilon=$ $\left(\Delta \log \left(A_{1}\right), \ldots, \Delta \log \left(A_{n}\right)\right)^{\prime}$, have on GDP. In particular, given Eq. (4), we have that

$$
\Delta \log (Y)=m \gamma^{\prime} \Delta \varepsilon
$$

Denoting the variance of a productivity shock in sector $i$ as $\sigma_{i}^{2}=\operatorname{var}\left(\Delta \varepsilon_{i}\right)$ and using the assumption that exogenous productivity terms are uncorrelated across sectors we can write GDP volatility defined as $\sigma_{Y}^{2}=\operatorname{var}(\Delta \log (Y))$ as follows:

$$
\sigma_{Y}^{2}=m^{2} \sum_{i} \gamma_{i}^{2} \sigma_{i}^{2}
$$

The term $\sum_{i} \gamma_{i}^{2} \sigma_{i}^{2}$ is referred to as fundamental volatility in Carvalho and Gabaix (2013) and 
granular volatility in Gabaix (2011). It describes volatility arising from idiosyncratic shocks to TFP at the sectoral level, pondered by the Domar weights. Fundamental volatility is multiplied by the term $m^{2}$ which describes the contribution of saving and labor supply decisions to aggregate volatility.

Based on Eq. (7), the model that we take to the data in order to explain GDP volatility in each period $t$ is the following:

$$
\sigma_{Y t}^{2}=m_{t}^{2} \sum_{i} \gamma_{i t}^{2} \sigma_{i t}^{2}
$$

The terms $m_{t}, \gamma_{i t}$ and $\sigma_{i t}$ denote respectively the multiplying factor, the Domar weight and the TFP volatility of sector $i$ in year $t$, thus computed using data in year $t$ (see Section 3 for details). Eq. (8) is similar to the empirical model implemented in Carvalho and Gabaix (2013) since it links the volatility of GDP to sectoral volatilities and Domar weights, but with the following important differences. First, in defining the multiplier $m_{t}$ we allow for heterogeneity in capital and labor shares, as well as heterogeneity in the shares of intermediate inputs across sectors. This enables us to be consistent with input-output data, resulting in a time-varying expression for production elasticities, i.e. $\alpha_{i t}$ and $w_{i t}$, and thus for the multiplying factor. In the presence of production input shares $\alpha$ and $w$ homogeneous across sectors and setting $\varphi=1$, the multiplier reduces to the expression implemented in Carvalho and Gabaix (2013)

$$
m=\frac{1+\phi}{1-\alpha}
$$

which is kept constant over time in their analysis. By considering a time-varying multiplier based on Eq. (5), where production elasticities are varying over time and calculated using input-output data, we take into account the time-varying contribution of labor supply and savings decisions to aggregate volatility. Second, we allow for time-varying sectoral TFP volatilities. This choice is motivated by previous empirical work which linked changes in GDP volatility to changes in sectoral volatility (see e.g. McConnell and Perez-Quiros, 2000; Moro, 2012). This enables us to highlight the impact that changes in the covariance between Domar weights and sectoral TFP volatilities had on changes in GDP volatility.

In what follows we show that $i$ ) our model calibrated to US data can explain the pattern of 
aggregate volatility $i$ ) by means of counterfactual analysis, we are able to disentangle the role played by time-varying sectoral TFP volatilities, asymmetric sectoral weights and the covariance between $\gamma_{i}$ and $\sigma_{i}$ in explaining aggregate volatility.

\section{Calibration}

A detailed description of the data used to construct all measures below is provided in Online Appendix B. Following Carvalho and Gabaix (2013), we consider both a rolling window and an instantaneous measure of GDP volatility. In order to obtain the first measure, we construct the series of quarterly HP-detrended log real GDP, denoted as $\hat{y}$, and then compute the variance at each quarter $q$ using a centered rolling window of 20 quarters:

$$
\sigma_{R W, q}^{2}=\operatorname{var}\left(\hat{y}_{\tau}\right) \quad \text { for } \tau \in[q-20, q+20]
$$

To obtain volatility in year $t$, denoted by $\sigma_{R W, t}^{2}$, we take the average of $\sigma_{R W, q}^{2}$ over the quarters of year $t$. To compute the second measure of GDP fluctuations we first estimate an AR(1) model on the quarterly growth rate of real GDP, and then use residuals $e_{q}$ to obtain the series of annualized instantaneous variance as $4 e_{q}^{2}$. We then compute the average of $4 e_{q}^{2}$ over the quarters of year $t$ to obtain

$$
\sigma_{t}^{2}=\sum_{q=1}^{4} e_{t: q}^{2},
$$

where $t: q$ denotes the quarter $q$ of year $t$, and finally obtain the instantaneous measure of GDP volatility $\sigma_{I V, t}^{2}$ using the HP-trend of $\sigma_{t}^{2}$.

We calibrate our model using input-output data from Dale Jorgenson and Associates (see Jorgenson et al., 2005) to explain GDP volatility, measured both as rolling window (RW) and as instantaneous volatility (IV). The dataset contains input-output yearly tables for 88 sectors for the US economy, ranging from 1960 to 2005. In order to broaden our analysis and study whether the 2007 financial crisis has marked the end of the "great moderation", we extended the original dataset using the BEA-BLS Integrated Industry-Level Production Account database, ranging from 1988 to 2018. To make our results comparable to previous literature, we consider the same total of 77 sectors analyzed in Carvalho and Gabaix (2013) (see Online Appendix B for details). 
In each year $t$ we compute the shares $\alpha_{i t}$ as the ratio between capital income and total income of primary inputs used by sector $i$ in that year. The shares $w_{i t}$ are computed as the ratio between the sum of the nominal values of all intermediate inputs used by each sector $i$ in that year $t$, and the nominal value of gross industry output. The Domar weights $\gamma_{i t}$ are computed as the ratio between nominal output of sector $i$ and nominal GDP in year $t$. For both datasets, sectoral changes in TFP $\Delta \varepsilon$ are computed using standard TFP accounting with intermediate inputs (see e.g. Jorgenson et al., 1987). In order to obtain a time-varying measure of sectoral volatilities we compute $\sigma_{i t}^{2}$ as the variance of $\Delta \varepsilon_{i t}$ using a 10 -years rolling window: ${ }^{3}$

$$
\sigma_{i t}^{2}=\operatorname{var}\left(\Delta \varepsilon_{i \tau}\right) \quad \text { for } \tau \in[t-5, t+5]
$$

In order to maximize the amount of data for the post-financial crisis period, volatility in the last 5 years of the sample, i.e. 2014-2018, is computed using asymmetric windows of decreasing length.

We set the Frisch elasticity $\phi=1.5$, which is consistent with usual calibrations used in the macroeconomic literature. This value of the Frisch elasticity implies a ratio between the standard deviations of hours worked and output equal to $3 / 5$, in line with empirical data. Finally, consistently with e.g. Cooper and Haltiwanger (2006), we assume convex capital adjustment cost and set $\varphi=5$. The implied ratio between the standard deviations of capital stock and output is $1 / 5$, in line with empirical data. ${ }^{4}$

In what follows we use rolling window measures of GDP and sectoral TFP volatilities as our benchmark. ${ }^{5}$ Robustness of the results to the alternative instantaneous volatility measure are reported in Online Appendix C.

\footnotetext{
${ }^{3}$ The window's length is consistent both with the number of years used in Carvalho and Gabaix (2013) and with the length used to compute GDP volatility.

${ }^{4}$ The standard deviation of labour supply in the model is $\operatorname{std}(\log (H))=\frac{\phi}{1+\phi} \operatorname{std}(\log (Y))$ and the standard deviation of the capital stock is $\operatorname{std}(\log (K))=\frac{1}{\varphi} \operatorname{std}(\log (Y))$ (see Eqs. (A.18) and (A.18) in Online Appendix A). The ratio between the observed standard deviations of the cyclical components of hp-filtered annual average weekly hours and annual real gdp is 0.59 . The ratio between the observed standard deviations of the cyclical components of hp-filtered annual real capital stock and annual real GDP is 0.19. Observed standard deviations are computed using US data from the Federal Reserve Economic Database.

${ }^{5}$ We choose this benchmark because, by considering an average over multiple periods, it allows us to reduce the impact of outliers on computed volatility.
} 


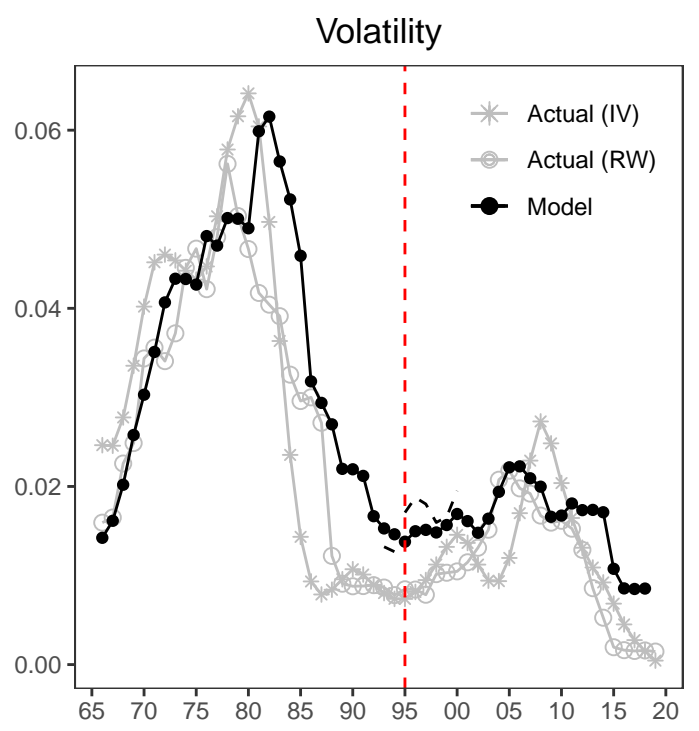

Figure 1: Actual GDP volatility computed using a rolling-window estimate (RW) and HP-filtered instantaneous volatility (IV) together with GDP volatility implied by our baseline model in Eq. (8). All values have been multiplied by 100 to improve readability. Red dashed vertical line marks cut-off year between model-implied volatility computed using DJA and BEA-BLS datasets. Dashed lines to the right (resp. left) of the cut-off year refer to aggregate volatility computed using the DJA (resp. BEA-BLS) dataset.

\subsection{Fit of the model}

Fig. 1 displays actual GDP volatility computed using both the rolling-window estimate (RW) and the HP-filtered instantaneous volatility (IV), together with the GDP volatility implied by the model in Eq. (8). Given the windows' length used to compute sectoral volatilities, the model-implied GDP volatilities constructed using the Dale Jorgenson and Associates (DJA) and the BEA-BLS Integrated Industry-Level Production Account (BEA-BLS) datasets overlap from 1993 to 2000. As discussed below, we will use the first set of data to study the rise and fall of aggregate volatility from 1966 to 1994, while the second set of data will be used to study the build-up of aggregate volatility starting from 1995 and culminating in the financial crisis of 2007, and its subsequent decrease until 2018. The cut-off year 1995 is marked in Fig. 1 with a red dashed line, while black dashed line to the right (resp. left) of the cut-off year refer to model-implied aggregate volatility computed using the DJA dataset (resp. BEA-BLS dataset) for the overlapping years. The latter have been reported for the sake of completeness but will not be considered in the analysis.

Fig. 1 shows that the calibrated model is able to track the observed pattern of US GDP volatility over time. In particular, despite the fact that the peak in volatility is slightly shifted to the right, 


\begin{tabular}{|c|c|c|c|c|c|c|c|c|c|}
\hline & \multicolumn{3}{|c|}{ Time sample: 1966-1994 } & \multicolumn{3}{|c|}{$1995-2018$} & \multicolumn{3}{|c|}{$1966-2018$} \\
\hline \multirow[t]{2}{*}{$\mathrm{a}$} & -0.00 & -0.00 & -0.00 & -0.00 & 0.00 & 0.00 & -0.00 & -0.00 & -0.00 \\
\hline & $(-0.00,0.00)$ & $(-0.00,-0.00$ & $(-0.00,0.00)$ & $(-0.00,-0.00)$ & $0.00,0.0$ & $(-0.00,0.00)$ & $(-0.00,0.00)$ & $(-0.00,-0.00)$ & $(-0.00,0.00)$ \\
\hline \multirow[t]{2}{*}{$\mathrm{b}$} & 0.86 & & 0.76 & 1.44 & & 1.49 & 0.91 & & 0.84 \\
\hline & $(0.57,1.15)$ & & $(0.42,1.10)$ & $(1.30,1.59)$ & & $(1.26,1.71)$ & $(0.70,1.11)$ & & $(0.53,1.16)$ \\
\hline \multirow[t]{2}{*}{$\mathrm{c}$} & & 2.04 & 0.33 & & -1.34 & -2.00 & & 2.91 & 0.26 \\
\hline & & $(1.21,2.87)$ & $(-0.37,1.03)$ & & $3.48,0.8$ & $(-3.37,-0.64)$ & & $(2.22,3.60)$ & $(-0.59,1.10)$ \\
\hline$R^{2}$ & 0.74 & 0.58 & 0.74 & 0.80 & 0.04 & 0.88 & 0.83 & 0.69 & 0.83 \\
\hline
\end{tabular}

Table 1: OLS estimates with HAC 90\% confidence intervals between brackets. The measure $\bar{\sigma}_{Y t}^{2}$ is obtained as $\bar{\sigma}_{Y t}^{2}=m_{t}^{2} \sum_{i} \gamma_{i t}^{2} \sigma_{i}^{2}$, where $\sigma_{i}$ denotes constant sectoral TFP volatility of sector $i$, i.e. computed over the whole relevant time sample, while $\sigma_{Y t}^{2}$ is defined in Eq. (8).

the model reproduces the "great volatility" and the subsequent "great moderation" episodes as well as the "pre-crisis volatility buildup" and the following decline in GDP volatility as the US went through a period of "great moderation again". In Table 1 we evaluate the goodness of fit of our model and we compare it with a model with constant sectoral TFPs. To this end, we estimate the following equation

$$
\sigma_{R W, t}^{2}=a+b \sigma_{Y t}^{2}+c \bar{\sigma}_{Y t}^{2}+\eta_{t}
$$

where $\sigma_{R W, t}^{2}$ denotes rolling-window estimate of actual GDP volatility, $\sigma_{Y t}^{2}$ is GDP volatility implied by the model with time-varying sectoral TFP volatilities in Eq. (8), and $\bar{\sigma}_{Y t}^{2}$ describes GDP volatility implied by the model with constant sectoral TFP volatilities $\sigma_{i}$ computed over the whole sample. We first perform the estimation using the DJA and BEA-BLS datasets separately, i.e. dividing in subsamples 1966-1994 and 1995-2018, and then we use the merged dataset and perform the estimation on the full sample.

Considering the 1966-1994 subsample, the first column of Table 1 shows that volatility $\sigma_{Y t}^{2}$ explains about $74 \%$ of actual GDP volatility $\sigma_{R W, t}^{2}$, while the second column shows that volatility $\bar{\sigma}_{Y t}^{2}$ is only able to explain about $58 \%$ of actual GDP volatility. The third column of Table 1 shows instead that, when both measures $\sigma_{Y t}^{2}$ and $\bar{\sigma}_{Y t}^{2}$ are included in the regression, the latter is not significant. Considering the 1995-2018 subsample, the fourth and fifth columns of Table 1 show that the model with time-varying volatility explains $80 \%$ of observed volatility, while the model with constant volatility explains only $4 \%$. When both $\sigma_{Y t}^{2}$ and $\bar{\sigma}_{Y t}^{2}$ are included in the regression, the coefficient associated to the latter is negative and significantly different from zero. 
These results are confirmed when considering the full sample 1966-2018. Comparing the seventh and eighth column of Table 1 we observe that the time-varying and the constant volatility models explain respectively $83 \%$ and $69 \%$ of actual GDP volatility. The last column shows that when both measures are included in the regression, the constant volatility measure is not significant.

Overall, these results show the ability of the model to track observed GDP volatility and highlight the importance of time-varying sectoral volatilities to explain the dynamics of aggregate fluctuations. ${ }^{6}$ However, it is difficult to interpret the regression results in terms of the relative importance of time-varying sectoral volatility and time-varying Domar weights in explaining aggregate volatility. To this end, in the next section we decompose changes in fundamental volatility to quantify the relative contributions of sectoral volatilities and Domar weights.

\subsection{Relative contributions of sectoral weights and volatilities}

In order to stress the pivotal role of idiosyncratic volatilities for aggregate fluctuations, we measure the relative contributions of changes in both Domar weights and sectoral TFP volatilities, to changes in fundamental volatility. Focusing on fundamental volatility rather than on the model-implied volatility including the multiplying factor allows us to obtain a simple characterization of such relative contributions. Recalling the definition of fundamental volatility as the combination of sectoral TFP volatilities pondered by the Domar weights, the change in fundamental volatility between two time periods $t_{1}$ and $t_{2}$ can be written as $\sum_{i} \gamma_{i, t_{2}}^{2} \sigma_{i, t_{2}}^{2}-\sum_{i} \gamma_{i, t_{1}}^{2} \sigma_{i, t_{1}}^{2}$. We can then decompose this difference to isolate the impacts of changes in $\gamma_{i}$ and $\sigma_{i}$ relative to the total change in fundamental volatility as

$$
\frac{\sum_{i} \bar{\gamma}_{i}^{2}\left(\sigma_{i, t_{2}}^{2}-\sigma_{i, t_{1}}^{2}\right)}{\sum_{i} \gamma_{i, t_{2}}^{2} \sigma_{i, t_{2}}^{2}-\sum_{i} \gamma_{i, t_{1}}^{2} \sigma_{i, t_{1}}^{2}}+\frac{\sum_{i} \bar{\sigma}_{i}^{2}\left(\gamma_{i, t_{2}}^{2}-\gamma_{i, t_{1}}^{2}\right)}{\sum_{i} \gamma_{i, t_{2}}^{2} \sigma_{i, t_{2}}^{2}-\sum_{i} \gamma_{i, t_{1}}^{2} \sigma_{i, t_{1}}^{2}}=1
$$

where $\bar{\gamma}_{i}^{2}=\left(\gamma_{i, t_{2}}^{2}+\gamma_{i, t_{1}}^{2}\right) / 2$ and $\bar{\sigma}_{i}^{2}=\left(\sigma_{i, t_{2}}^{2}+\sigma_{i, t_{1}}^{2}\right) / 2$. The first term describes the relative importance of the change in the idiosyncratic volatilities between $t_{1}$ and $t_{2}$ scaled by the average Domar weights in $t_{1}$ and $t_{2}$, while the second term describes the relative importance of the change in the Domar weights between $t_{1}$ and $t_{2}$ scaled by the average idiosyncratic volatility in $t_{1}$ and $t_{2}$. Both terms

\footnotetext{
${ }^{6}$ In Online Appendix $\mathrm{C}$ we perform a series of robustness checks. We show that the model retains the ability to reproduce observed GDP volatility - computed both with the rolling window and the instantaneous volatility methods - also using different measures of time-varying sectoral volatility.
} 
have a simple and intuitive interpretation: the first term measures the change in volatility that would have occurred if only sectoral TFP had changed and Domar weights had remained constant at their average level (as a fraction of total change in fundamental volatility), while the second term measures the change that would have taken place if the Domar weights had been the only variables to change (as a fraction of total change in fundamental volatility) with sectoral TFPs at their average level. We compute the relative contributions of changes in Domar weights and in sectoral TFP volatilities for the historical episodes of interest, classified as "great volatility" (1966-1982), "great moderation" (1983-1994), "pre-crisis volatility buildup" (1995-2005), "great moderation again" (2006-2018). Computing the two terms for the "great volatility" period spanning from 1966 to 1982 , we find that $78 \%$ of the increase in fundamental volatility is explained by the change in idiosyncratic volatilities, while $22 \%$ is explained by the change in the Domar weights. During the "great moderation" between 1983 and 1994, 57\% of the reduction in volatility is explained by the sectoral volatility term and only $43 \%$ by the change in the Domar weights. Between 1995 and $2005,83 \%$ of the increase in volatility is explained by the sectoral volatility term against the $17 \%$ contribution of the Domar weights term. On the other hand, $107 \%$ of the decline in volatility occurred between 2006 and 2018 is explained by changes in sectoral volatilities, while $-7 \%$ is attributed to changes in Domar weights, meaning that changes in Domar weights alone would predict an increase, instead of a decrease, in aggregate volatility.

These results show once again that changes in sectoral TFP volatility have significant impact on the dynamics of GDP volatility. In the next section we introduce a series of counterfactual exercises aimed at understanding in details the determinants of aggregate volatility.

\section{Counterfactual analysis}

In this section we describe a series of counterfactual exercises which will be used in Section 5 to assess the impact of the different terms in Eq. (8) on aggregate volatility from 1966 to 2018. In particular, the counterfactuals allow to disentangle the contributions to observed changes in GDP volatility of $i$ ) changes in sectoral volatility, $i i$ ) changes in aggregate intermediate goods intensity in production and $i i i)$ changes in the distribution of Domar weights, reflecting changes in both the vector $\beta$ and the input-output network $W$. As discussed in Section 5, each of these elements 
played a role during the four episodes of interest, namely "great volatility" (1966-1982), "great moderation" (1983-1994), "pre-crisis volatility buildup" (1995-2005), "great moderation again" (2006-2018).

In the first counterfactual we evaluate the impact of sectoral TFP volatilities $\sigma_{i t}^{2}$ on aggregate GDP volatility in the absence of an input-output network. To this end, we compute aggregate volatility setting $w_{i j}=0$ for all sectors $i, j$. We label this scenario as "No I-O". In this case the vector of Domar weights is simply equal to the vector of exponents in final good production, which we set homogeneous across sectors, i.e. $\gamma_{i}=\beta_{i}=1 / n$ for all $i$. The scalar $\Gamma_{t}$ in Eq. (5) which defines the multiplying factor $m_{t}$ is then given by

$$
\Gamma_{t}=\frac{1}{n} e^{\prime}\left(\frac{1}{\varphi} k_{s t}+\frac{\phi}{1+\phi} h_{s t}\right), \quad(\text { No I-O })
$$

where $e=(1, \ldots, 1)^{\prime}$ and the $i$-th elements of vectors $k_{s t}$ and $h_{s t}$ are now given respectively by $\alpha_{i t}$ and $\left(1-\alpha_{i t}\right)$ computed using actual input-output tables. The time variation of aggregate volatility in this case is described by

$$
\sigma_{Y t}^{2}=m_{t}^{2} \frac{1}{n^{2}} \sum_{i} \sigma_{i t}^{2}, \quad(\text { No I-O })
$$

and it depends only on sectoral TFP volatilities and production elasticities for capital and labor. Fig. 2(a) reports GDP volatility in the No $\mathrm{I}-\mathrm{O}$ scenario and relates it to the baseline volatility implied by the model in Eq. (8) and labeled "Asy I-O" (see below). The top panel of Fig. 2(b) displays volatility in the No I-O scenario together with actual GDP volatility. Fig. 2(a) shows that aggregate volatility implied by sectoral volatilities alone is low when compared to the baseline. In fact, the average ratio between volatilities in the No I-O scenario and the baseline is about 0.11. However, the top panel of Fig. 2(b) shows that the No I-O aggregate volatility exhibits a pattern similar to actual GDP volatility, with a correlation coefficient of approximately 0.85 (significant at the $5 \%$ level). This means that changes in sectoral volatilities alone are an important engine for the time variation of aggregate volatility, but the network of production linkages plays an important amplification role.

In order to assess the importance of the input-output network for aggregate volatility, we start by considering an hypothetical symmetric structure of production linkages. In this second coun- 


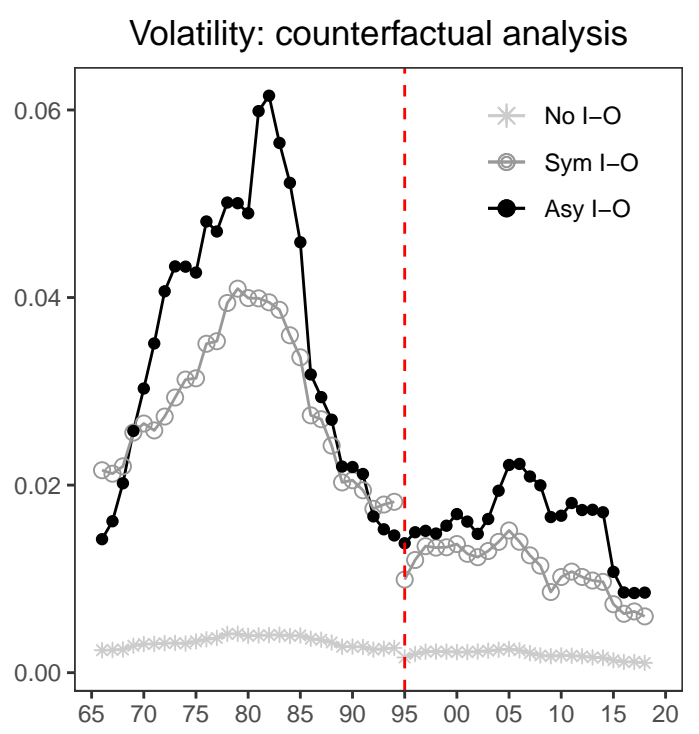

(a)
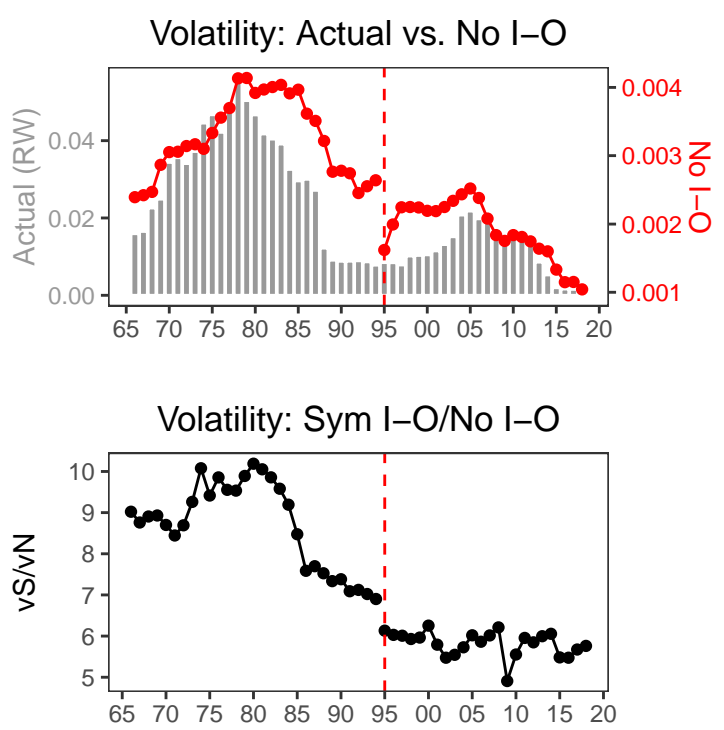

(b)

Figure 2: Panel (a): Model-implied volatilities in the cases of no input-output network (No I-O), symmetric (Sym I-O) and asymmetric (Asy I-O) input-output network. Panel (b)-top: Actual aggregate volatility (gray bars and left scale) and No I-O volatility (red dotted line and right scale). Panel (b)-bottom: Ratio between Sym I-O volatility and No I-O volatility. Red dashed vertical lines mark cut-off year between volatility computed using DJA and BEA-BLS datasets.

terfactual we thus maintain homogeneous exponents in final good production $\beta_{i}=1 / n$ and we calibrate the total intermediate input shares $w_{i t}$ using input-output data. The symmetric inputoutput network is then obtained by setting $w_{i j t}=w_{i t} / n$ for all $j$. We label this scenario as "Sym I-O”. In this case the Domar weights sum up to the observed total nominal value of sales over GDP, but they are homogeneous across sectors. Therefore we compute the homogeneous Domar weights as $\gamma_{i t}=\frac{1}{n} \sum_{j} \frac{p_{j t} Q_{j t}}{Y_{t}}=\bar{\gamma}_{t}$ for all $i$. The scalar $\Gamma_{t}$ in Eq. (5) is thus obtained as

$$
\Gamma_{t}=\bar{\gamma}_{t} e^{\prime}\left(\frac{1}{\varphi} k_{s t}+\frac{\phi}{1+\phi} h_{s t}\right), \quad(\mathrm{Sym} \mathrm{I-O})
$$

and the multiplier $m_{t}$ is computed accordingly. The evolution of GDP volatility is then given by

$$
\sigma_{Y t}^{2}=m_{t}^{2} \bar{\gamma}_{t}^{2} \sum_{i} \sigma_{i t}^{2} . \quad(\text { Sym I-O })
$$

The variation of volatility over time in this scenario depends also on the average level of sales per unit of GDP, i.e. $\bar{\gamma}_{t}$, which is a measure of the importance of intermediate inputs in production. 
Fig. 2(a) reports GDP volatility implied by the second counterfactual and relates it to the first counterfactual and the baseline. By comparing the volatilities obtained in the Sym I-O and the No I-O scenarios we isolate the amplifying effect of a symmetric input-output network. The mere presence of such a network implies the propagation of idiosyncratic productivity shocks across sectors via production linkages.

In order to better visualize the amplifying effect, the bottom panel of Fig. 2(b) plots the ratio between the volatilities in the Sym I-O and No I-O scenarios denoted for simplicity as $\mathrm{vS}_{t} / \mathrm{vN}_{t}$ and given by

$$
\frac{\mathrm{vS}_{t}}{\mathrm{vN}_{t}}=\frac{\mathrm{mS}_{t}}{\mathrm{mN}_{t}} n^{2} \bar{\gamma}_{t}^{2}
$$

where $\mathrm{mS}_{t} / \mathrm{mN}_{t}$ denotes the ratio between the squared multiplying factors $m_{t}$ in the Sym I-O and No I-O scenarios. The ratio above makes clear that the amplifying effect of the symmetric input-output network over time crucially depends on the time variation of the intermediate input intensity in the economy. ${ }^{7}$ The higher the intermediate input intensity of the production structure, the higher the impact of sectoral shocks on GDP.

Finally, we evaluate the contribution of asymmetries in the vector of shares of intermediate goods in final good production $\beta$ and in the input-output network $W$ to aggregate volatility. In this case the sectoral Domar weights are thus given by observed gross nominal industry output over GDP. This corresponds to the baseline model in Eq. (8) reported below for convenience and labeled as "Asy I-O":

$$
\sigma_{Y t}^{2}=m_{t}^{2} \sum_{i} \gamma_{i t}^{2} \sigma_{i t}^{2}
$$

Fig. 2(a) reports model-implied GDP volatility under Asy I-O. The difference between the Sym I-O and the Asy I-O scenarios is that in the latter we introduce asymmetry in the production structure by considering observed Domar weights. This allows us to isolate the impact of asymmetries in the distribution of Domar weights, which correspond to asymmetries in the vector of shares in final good production and in the structure of production linkages.

Sectoral TFP volatilities are an important source of GDP fluctuations but, as noted before, the implied volatility in the absence of production linkages is too low. Introducing a symmetric input-

\footnotetext{
${ }^{7}$ The relation between $\mathrm{vS}_{t} / \mathrm{vN}_{t}$ and $\bar{\gamma}_{t}$ is non linear as $\bar{\gamma}_{t}$ also enters the expression of $m_{t}$ in the Sym I-O scenario. The correlation between $\mathrm{vS}_{t} / \mathrm{vN}_{t}$ and $\bar{\gamma}_{t}$ is $\approx 0.99$.
} 
output layer to the model amplifies micro-level volatilities because it allows idiosyncratic shocks to spread through the network. However, the change in the intensity of intermediate goods in production is not able to fully explain observed changes in aggregate volatility. By comparing the Sym I-O and Asy I-O scenarios it is clear how the asymmetric structure of the production system had an important role for aggregate dynamics. Note that the only difference between Sym I-O and Asy I-O is the distribution of Domar weights across sectors. The comparison of these scenarios reveals that the role played by asymmetries in shaping aggregate volatility has greatly changed in time. This time variation could simply be explained by a change of the degree of heterogeneity in Domar weights over time, or it could be due to a change in the interaction between similarly heterogenous Domar weights and sectoral TFP volatilities. In the following section we investigate this issue further.

\subsection{The time-varying role of asymmetry}

Consider the ratio between volatilities in the Asy I-O and Sym I-O scenarios denoted for simplicity by $\mathrm{vA}_{t} / \mathrm{vS}_{t}$ :

$$
\frac{\mathrm{vA}_{t}}{\mathrm{vS}_{t}}=\frac{\mathrm{mA}_{t}}{\mathrm{mS}_{t}} \frac{\sum_{i} \gamma_{i t}^{2} \sigma_{i t}^{2}}{\bar{\gamma}_{t}^{2} \sum_{i} \sigma_{i t}^{2}},
$$

where $\mathrm{mA}_{t} / \mathrm{mS}_{t}$ denotes the ratio between the squared multiplying factors $m_{t}$ in the Asy I-O and Sym I-O scenarios. The ratio between the volatility with asymmetric and symmetric production structures depends on the ratio between the multipliers and on a second term which in turn depends, unsurprisingly, on the distribution of $\gamma_{i}$, and in particular on the product between the vector of squared Domar weights and the vector of sectoral volatilities in each time period $t$. To help the intuition, it turns out to be convenient to rewrite the expression above in terms of cross-sectional population moments to obtain

$$
\frac{\mathrm{vA}}{\mathrm{vS}}=\frac{\mathrm{mA}}{\mathrm{mS}}\left(\frac{E(\gamma)^{2}+\operatorname{var}(\gamma)}{E(\gamma)^{2}}+\frac{\operatorname{cov}\left(\gamma^{2}, \sigma^{2}\right)}{E(\gamma)^{2} E\left(\sigma^{2}\right)}\right)
$$

where we have suppressed the time subscript $t$ for notational simplicity. Let us define the terms Het $\equiv\left(E(\gamma)^{2}+\operatorname{var}(\gamma)\right) / E(\gamma)^{2}$ and $C o v \equiv \operatorname{cov}\left(\gamma^{2}, \sigma^{2}\right) /\left(E(\gamma)^{2} E\left(\sigma^{2}\right)\right)$. The Het term describes how the heterogeneity of the Domar weights evolved over time. When the Domar weights are 
homogeneous across sectors $(\operatorname{var}(\gamma)=0)$, the term Het is equal to 1 . The Het term increases with the cross-sectional variance of $\gamma$, i.e. with the degree of heterogeneity. We remark that the distribution of Domar weights also impacts the ratio of multipliers $\mathrm{mA} / \mathrm{mS}$. The Cov term shows that the way in which the covariance between the vector of (squared) Domar weights $\gamma^{2}$ and the vector of sectoral TFP volatilities $\sigma^{2}$ evolves over time has an impact on aggregate fluctuations. Fig. 3 displays the evolution over time of terms $\mathrm{vA} / \mathrm{vS}, \mathrm{mA} / \mathrm{mS} \times$ Het and $\mathrm{mA} / \mathrm{mS} \times$ Cov .

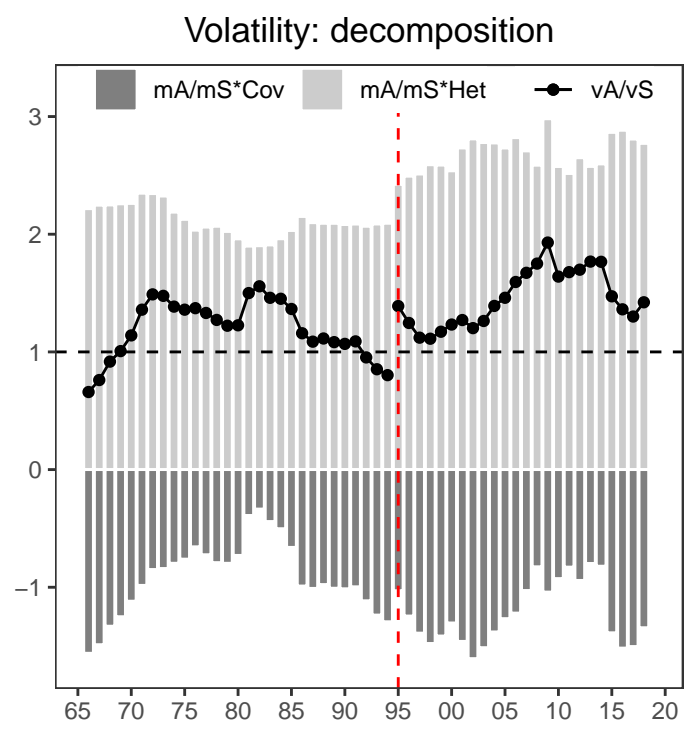

Figure 3: Evolution of terms vA/vS (black dotted line), $\mathrm{mA} / \mathrm{mS} \times$ Het (light gray bars) and $\mathrm{mA} / \mathrm{mS} \times$ Cov (dark gray bars) over time. Red dashed vertical lines mark cut-off year between volatility computed using DJA and BEA-BLS datasets.

Values of the ratio $\mathrm{vA} / \mathrm{vS}>1$ imply that the asymmetric structure of the production system has an amplifying effect on aggregate volatility. Viceversa, when vA/vS $<1$, asymmetry has a dampening effect on aggregate volatility. The evolution of vA/vS in Fig. 3 shows that the impact of asymmetry has changed throughout the years, sometimes having a magnifying effect (e.g. during the "great volatility"), and at other times having a dampening effect (e.g. during the "great moderation"). The ratio mA/mS (not shown in Fig. 3) has been relatively stable throughout the sample, ranging from 0.86 to 1.12 , and its time variation does not explain the evolution of $\mathrm{vA} / \mathrm{vS}$ (correlation coefficient $\approx 0.08$, not significantly different from 0 at the $5 \%$ level). On the other hand, the time variation of both $\mathrm{mA} / \mathrm{mS} \times$ Het and $\mathrm{mA} / \mathrm{mS} \times$ Cov significantly contribute to the explanation of changes in $\mathrm{vA} / \mathrm{vS}$ (correlation coefficients respectively $\approx 0.41$ and 0.46 , both 
significant at the $5 \%$ level). A description of their role during the historical episodes of interest is reported in the next section.

Before we proceed with the account of US volatility in the last 50 years, we rewrite for convenience the term $C o v$ as:

$$
\frac{\operatorname{cov}\left(\gamma^{2}, \sigma^{2}\right)}{E(\gamma)^{2} E\left(\sigma^{2}\right)}=\operatorname{corr}\left(\gamma^{2}, \sigma^{2}\right) \xi
$$

where $\operatorname{corr}\left(\gamma^{2}, \sigma^{2}\right)$ is the correlation between the squared Domar weights and the idiosyncratic

volatilities in each time period, while $\xi \equiv \frac{\operatorname{std}\left(\gamma^{2}\right) \operatorname{std}\left(\sigma^{2}\right)}{E(\gamma)^{2} E\left(\sigma^{2}\right)}$ is a scaling term accounting for dispersion and size of $\gamma^{2}$ and $\sigma^{2}$ in each time period. This formulation allows to easily interpret the timevarying interaction between Domar weights and TFP volatilities. We remark that $\operatorname{corr}\left(\gamma^{2}, \sigma^{2}\right)$ is always negative throughout the sample and it is positively correlated with $\mathrm{vA} / \mathrm{vS}$ (correlation coefficient $\approx 0.68$, significant at the $5 \%$ level), meaning that the amplifying effect of an asymmetric production structure can be traced back to an higher (less negative) scaled correlation between Domar weights and sectoral TFP volatilities.

\section{Aggregate volatility in the last 50 years}

In this section we provide an account of US GDP volatility in the last 50 years. We divide our analysis into 4 subperiods in order to explain: $i$ ) what caused the sharp increase observed in aggregate volatility between 1966 and 1982? ii) what accounts for the large decline in GDP fluctuations occurred between 1983 and 1994? iii) what is behind the buildup in GDP volatility observed in the pre-crisis period 1995 to 2005? iv) has the 2007 global financial crisis marked the end of the "great moderation"?

A first account of the history of aggregate volatility is provided in Fig. 4, where we aggregate the 77 sectors in our dataset in 7 macro-industries - Agriculture, Constructions, Energy, Finance, Manufacturing, Trade and Others - and compute their contributions to fundamental GDP volatility as

$$
\sigma_{\mathcal{S} t}^{2}=\sum_{i \in \mathcal{S}} \gamma_{i t}^{2} \sigma_{i t}^{2}
$$

where $\mathcal{S}$ represents the macro-industry. Fig. 4(a) stacks the fundamental volatility of each macro- 
industry (note that $\sum_{\mathcal{S}} \sigma_{\mathcal{S} t}^{2}$ is the total fundamental volatility in period $t$ ), while Fig. 4(b) displays the share of total fundamental volatility of each macro-industry, with darker colors associated to higher shares.

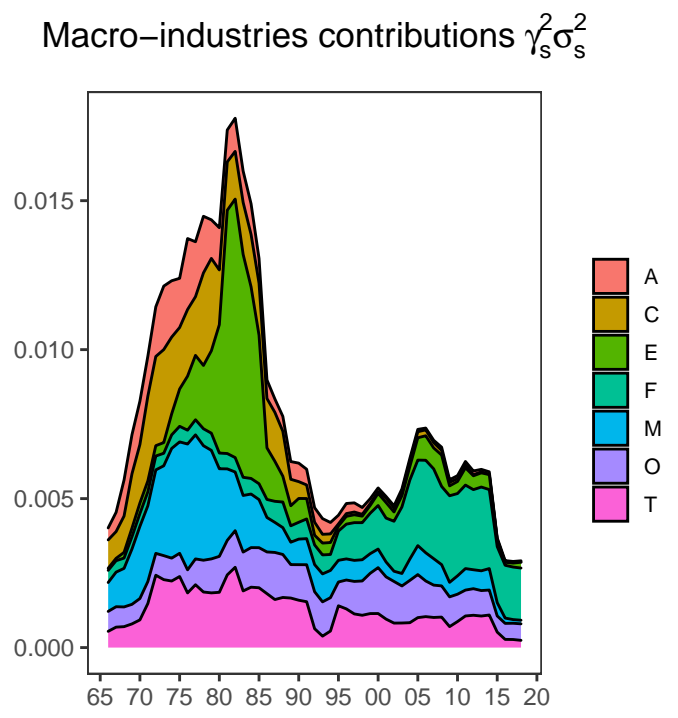

(a)

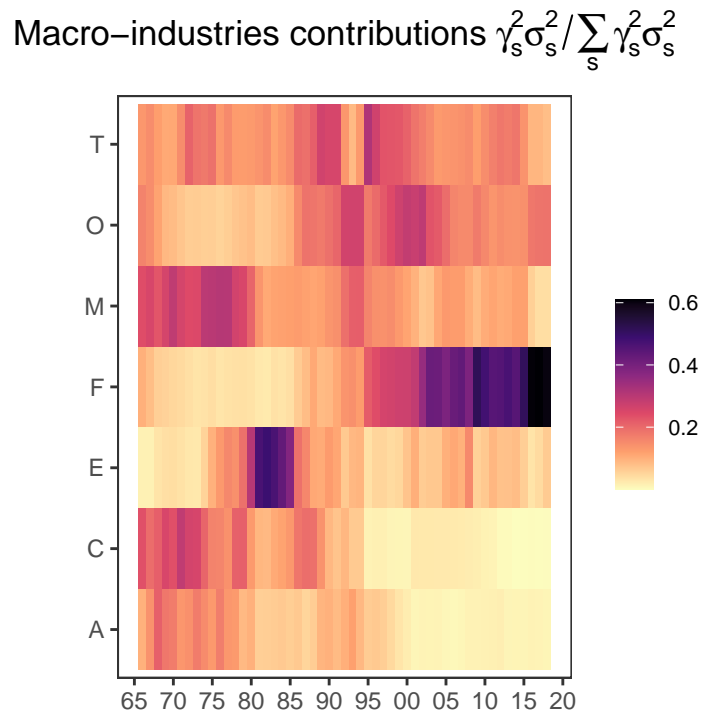

(b)

Figure 4: Panel (a): Time variation of contribution to fundamental volatility aggregated per macro-industries Agriculture (A), Construction (C), Energy (E), Finance (F), Manufacturing (M), Others (O) and Trade (T) (values multiplied by 100 to improve readability). Panel (b): Time variation of contribution to fundamental volatility aggregated per macro-industries as percentage of total fundamental volatility.

The "great volatility" has been initially driven by a volatility increase in sectors related to Agriculture, Construction, Manufacturing and Trade. Starting from 1973, volatility in Energyrelated sectors rapidly increased causing large GDP fluctuations and more than compensating decreasing volatilities in other sectors. At the peak of the "great volatility" in the early-1980s, the Energy macro-industry accounted for about $50 \%$ of total fundamental volatility. During the "great moderation" volatility declined in all macro-industries, with the largest drops observed in the macro-industries that contributed the most to the "great volatility". Towards the end of the "great moderation" in the mid-1990s, the volatility shares of different macro-industries were roughly comparable, ranging between about $10 \%$ and $20 \%$. After the "great moderation" period, the main driver for GDP fluctuations has been the Finance sector, whose importance for aggregate volatility gradually increased from mid-1990s until the end of the sample. In fact, both the "pre- 
crisis volatility buildup" and the "great moderation again" phases have been essentially led by the volatility dynamics of Finance-related sectors, accounting for about $40 \%$ of total fundamental volatility in the first phase and for about $60 \%$ in the second phase.

In the remainder of the section we discuss the role played by sectoral TFP volatilities, the overall intermediate input intensity of the production structure and the asymmetries in the shares of intermediate goods in final production and in the input-output network using the counterfactual analysis described in Section 4. Moreover, in order to quantify sectoral contributions to changes in aggregate fluctuations observed in each of the four episodes of interest, we use index $H_{i}\left(t_{1}, t_{2}\right)$ defined as

$$
H_{i}\left(t_{1}, t_{2}\right)=\frac{\gamma_{i, t_{2}}^{2} \sigma_{i, t_{2}}^{2}-\gamma_{i, t_{1}}^{2} \sigma_{i, t_{1}}^{2}}{\sum_{i} \gamma_{i, t_{2}}^{2} \sigma_{i, t_{2}}^{2}-\sum_{i} \gamma_{i, t_{1}}^{2} \sigma_{i, t_{1}}^{2}},
$$

measuring the contribution of a given sector $i$ to the change of aggregate volatility occurred between periods $t_{1}$ and $t_{2}$. As argued in Section 3.1, focusing on fundamental volatility rather than on the model-implied volatility including the multiplying factor allows us to obtain a simple characterization of such contributions. Results of a similar exercise are described in Carvalho and Gabaix (2013), but with constant sectoral volatilities. Considering time-varying TFP volatilities allows to identify sectors that had a sizeable impact on aggregate volatility, despite their importance in the production structure, measured by their Domar weights, remained roughly constant.

\section{6-1982: Great volatility}

The "great volatility" period was the result of a perfect storm, in which all factors contributed to a surge in GDP volatility. As shown in the upper panel of Fig. 2(b), average sectoral TFP volatility sharply increased between 1966 and 1982. The Sym I-O scenario in Fig. 2(a) shows that the impact of sectoral volatilities has been amplified by an increase in the intermediate input intensity of the production system (see also Fig. 2(b), lower panel), while the Asy I-O scenario shows that the interaction between asymmetric Domar weights and sectoral volatilities led to an even higher volatility at the aggregate level (see also Fig. 3).

As previously discussed, the impact of asymmetries on aggregate volatility positively depends on the degree of heterogeneity in the vector of Domar weights (Het term in section 4.1) and on the correlation between sectoral TFP volatility and Domar weights (Cov term in section 4.1). As shown 
in Fig. 3, heterogeneity in Domar weights had an overall decreasing trend between 1966 and 1982. Therefore, the magnifying impact of the asymmetry in the production structure (i.e. vA/vS > 1) in those decades can be traced back to changes in the correlation between Domar weights and sectoral volatilities (scaled by factor $\xi$ ). In other words, the increasingly higher impact of asymmetries on aggregate volatility can be explained by the fact that relatively volatile sectors became more "central" in the production network, i.e. their Domar weights increased, and relatively "central" sectors became more volatile.

Thus, from 1966 to 1982, the US economy witnessed $i$ ) an overall increase of sectoral volatility, ii) an increase in intermediate input intensity, iii) a higher (less negative) correlation between Domar weights and sectoral volatilities. All these factors led to a rapid increase in aggregate volatility during these years.

In order to further investigate such dynamics and understand which sectors contributed the most to the "great volatility", we consider the distribution of index $H_{i}(1966,1982)$ displayed in Fig. 5(a). The five most important sectors for the "great volatility" period, namely Oil and gas

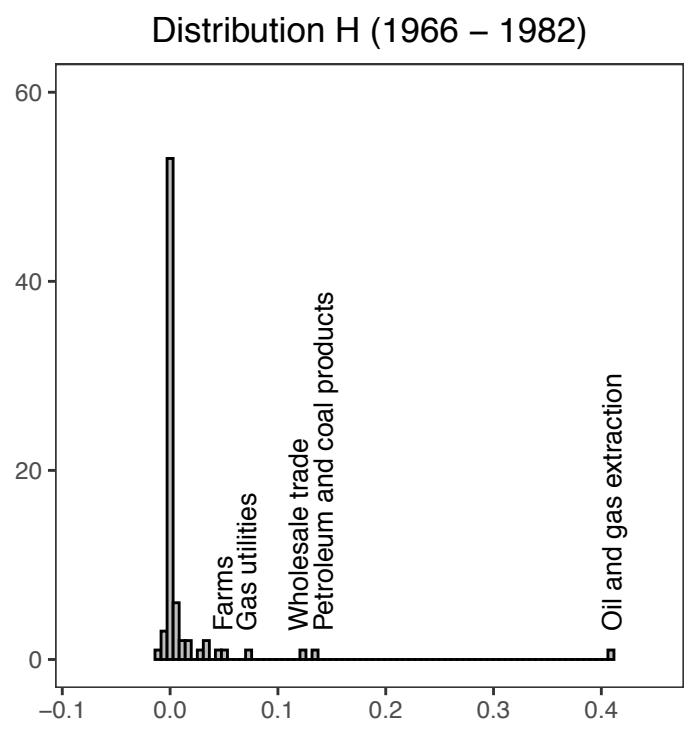

(a)

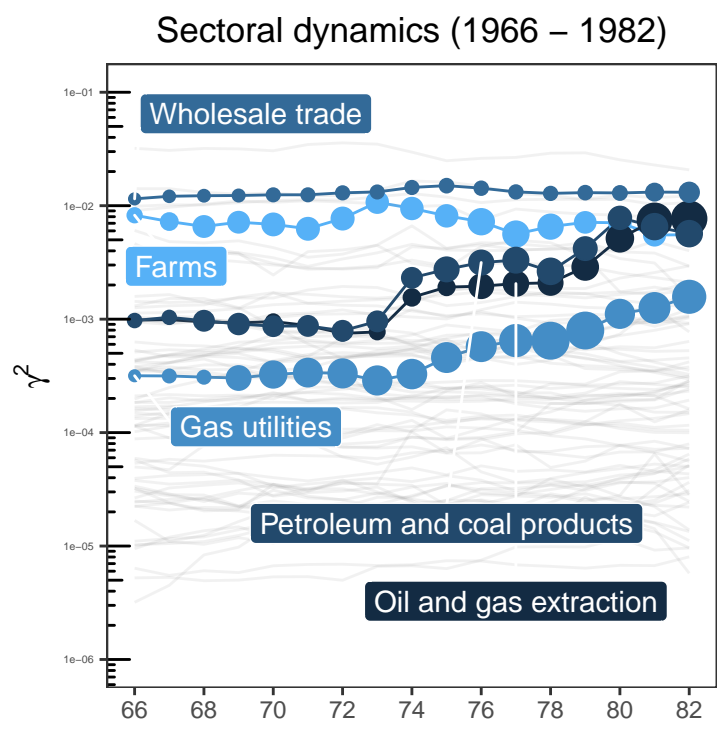

(b)

Figure 5: Panel (a): Distribution of $H_{i}(1966,1982)$. Labels show the 5 most relevant sectors. Panel (b): Time variation of $\gamma_{i}^{2}$ (in $\log _{10}$ scale) for first 5 sectors ranked according to measure $H_{i}(1966,1982)$. Darker to lighter color reflects decreasing sector importance according to $H_{i}$. Circle size is proportional to $\sigma_{i}^{2}$.

extractions, Petroleum and coal products, Wholesale trade, Gas utilities and Farms, jointly account 
for about $79 \%$ of the increase in aggregate volatility between 1966 and 1982, while sector Oil and gas extractions alone accounts for about $41 \%$ of such increase. Fig. 5(b) displays instead the Domar weights associated to each sector over time, with the size of the circles proportional to idiosyncratic volatility. For the sake of readability, we highlighted the five most important sectors according to $H_{i}(1966,1982)$, while darker to lighter color reflects decreasing sector importance according to $H_{i}$. As argued above, the increase in the correlation between Domar weights and sectoral TFP volatilities had a key role during the "great volatility". In fact, a significant part of the increase in (fundamental) volatility observed between 1966 and 1982 is due to the fact that $i$ ) some very large sectors in the US production structure, such as Farms and Wholesale trade, experienced an increase in their TFP volatility while their Domar weights remained roughly constant; ii) sectors related to fossil fuels (belonging to the Energy macro-industry) displayed an increase in both their importance in terms of Domar weights and their TFP volatility.

\section{3-1994: Great moderation}

The decline in average sectoral TFP volatility to levels observed prior to the "great volatility" (see Fig. 2(b), upper panel) and the drastic reduction in the intermediate input intensity (see Fig. 2(b), lower panel) have been important drivers of the "great moderation". Moreover, as shown by the downward trend of ratio vA/vS in Fig. 3, the role of asymmetries in the production structure varied over time and their impact on GDP volatility changed from being amplifying (vA/vS $>1$ ) to being dampening $(\mathrm{vA} / \mathrm{vS}<1)$. Since the Het term remained roughly stable between 1983 and 1994, the dampening effect is mostly due to the Cov term. In particular, less volatile sectors became relatively important in the production structure and relatively important sectors became less volatile.

The five most relevant sectors for the "great moderation" highlighted in Fig. 6(a), namely Oil and gas extraction, Construction, Wholesale trade, Petroleum and coal products and Gas utilities, are jointly responsible for about $83 \%$ of the decline in GDP volatility, while sector Oil and gas extractions alone accounts for about $43 \%$ of such decrease. As shown in Fig. 6(b), a significant part of the reduction in fundamental aggregate volatility leading to the "great moderation" is explained by the fact that sectors related to fossil fuels (Energy macro-industry) became less central in the production network and less volatile. On the other hand, the Construction and Wholesale trade sectors became less volatile while their Domar weights remained roughly constant. 


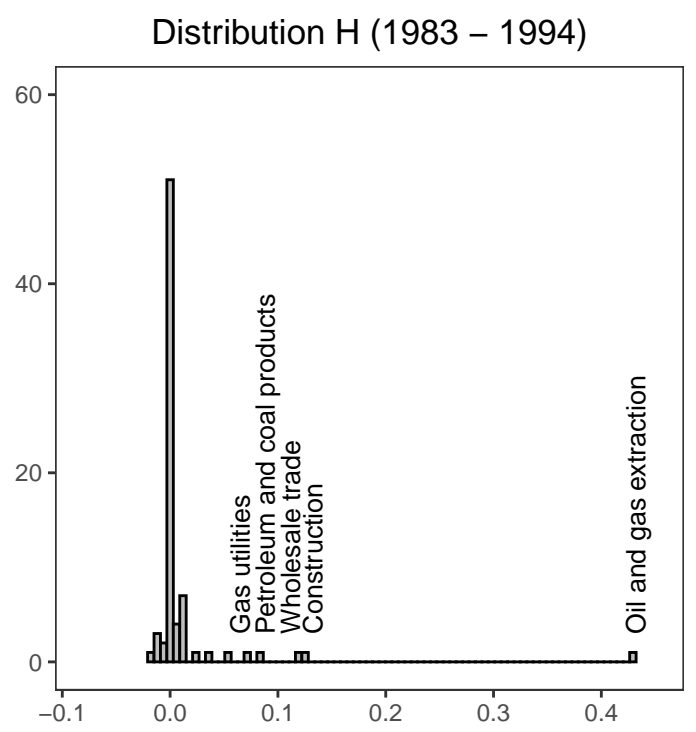

(a)

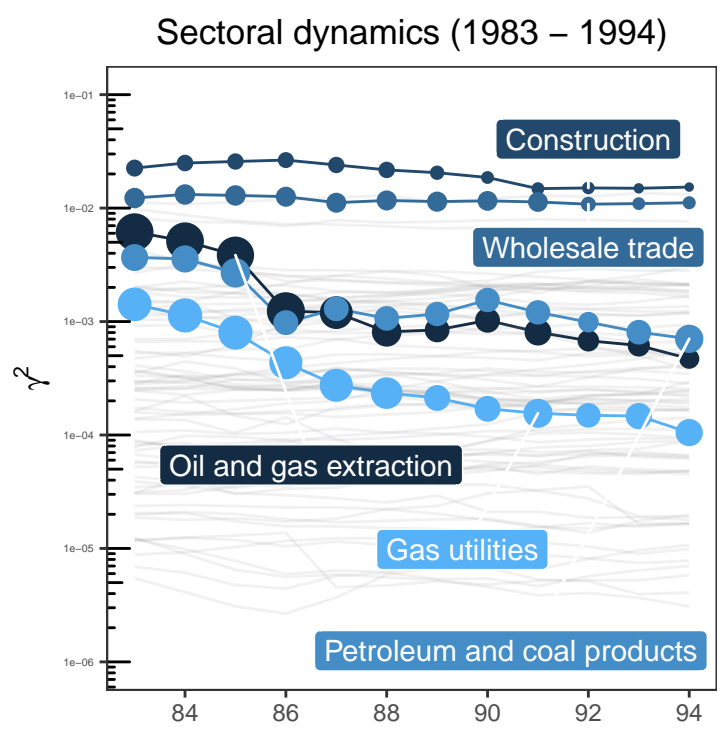

(b)

Figure 6: Panel (a): Distribution of $H_{i}(1983,1994)$. Labels show the 5 most relevant sectors. Panel (b): Time variation of $\gamma_{i}^{2}$ (in $\log _{10}$ scale) for first 5 sectors ranked according to measure $H_{i}(1983,1994)$. Darker to lighter color reflects decreasing sector importance according to $H_{i}$. Circle size is proportional to $\sigma_{i}^{2}$.

\section{5-2005: Pre-crisis volatility buildup}

After the sharp decrease observed during the "great moderation", sectoral TFP volatilities increased in the second half of 1990 s and throughout the first half of 2000s, providing the basis for the slow buildup in aggregate volatility observed before the 2007 global financial crisis (see Fig. 2(b), upper panel). The intermediate input intensity and the amplifying effect of asymmetries remained roughly stable during the decade 1995-2005 (see resp. lower panel of Fig. 2(b) and Fig. 3).

At the sectoral level, the largest contributor to the increase in aggregate fundamental volatility has been the Finance macro-industry. As shown in Fig. 7(a), finance-related sectors NonDepository financial institutions (including brokerage services and investment banks) and Insurance were among the five sectors that contributed the most to the volatility buildup and, as shown in Fig. 7(b), while their Domar weights remained roughly stable, their volatility increased in the decade 1995-2005. The combined contribution of these two finance-related sectors to the observed volatility surge accounted for about $52 \%$. The Real estate sector also had a sizeable impact, accounting for roughly $9 \%$ of the volatility increase, while overall, the contribution of the first five sectors highlighted in Figs. 7(a) and 7(b), amounts to 87\%. During the volatility buildup, while 


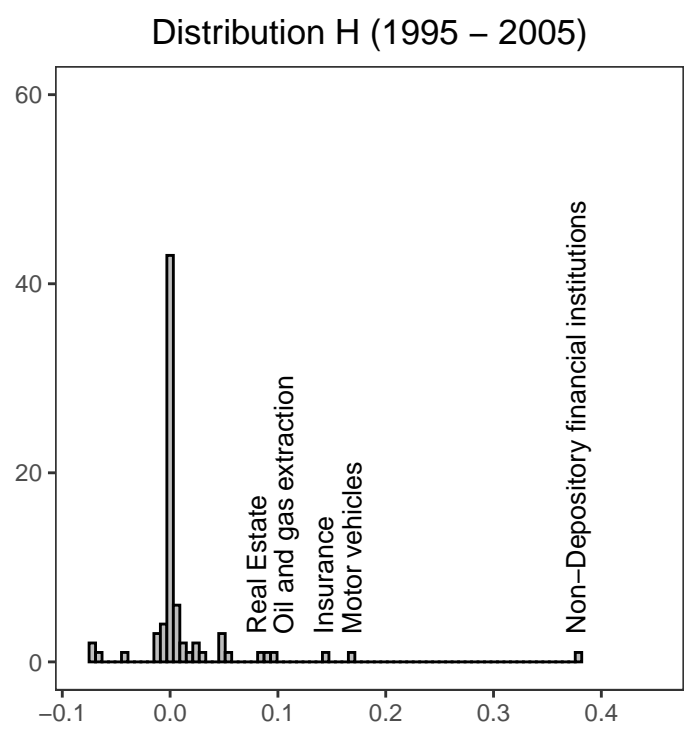

(a)

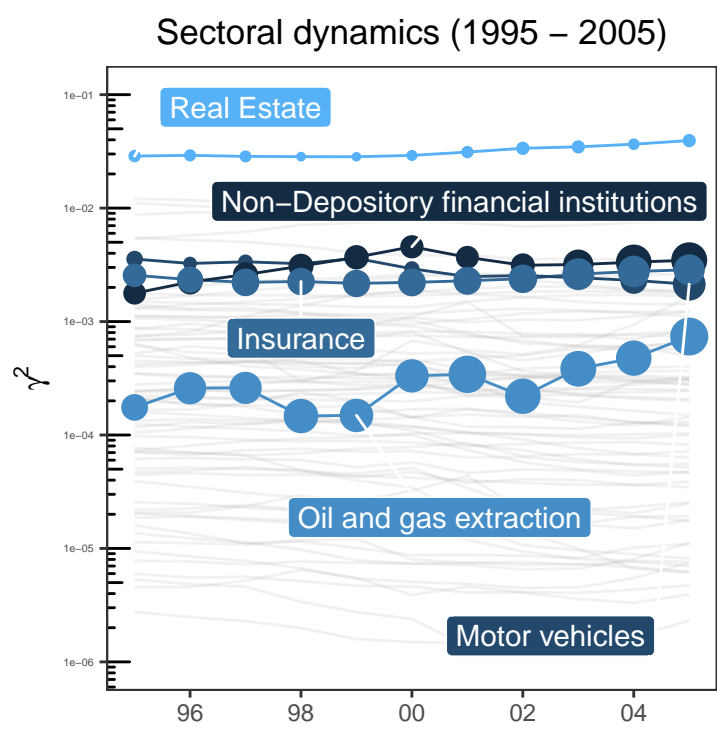

(b)

Figure 7: Panel (a): Distribution of $H_{i}(1995,2005)$. Labels show the 5 most relevant sectors. Panel (b): Time variation of $\gamma_{i}^{2}$ (in $\log _{10}$ scale) for first 5 sectors ranked according to measure $H_{i}(1995,2005)$. Darker to lighter color reflects decreasing sector importance according to $H_{i}$. Circle size is proportional to $\sigma_{i}^{2}$.

most sectors followed the general increase of volatility, few sectors had a clear opposite behavior (see Fig. 7(a)). Notably, Farms, Wholesale trade e Retail trade (excluding motor vehicles) had a negative $\mathrm{H}$ index. This implies that their volatility decreased in this period, partially compensating the increase in fundamental volatility caused by other sectors.

\section{6-2018: Great Moderation Again}

The pre-crisis volatility buildup ends with a volatility peak in 2005 and 2006. After 2006, GDP fluctuations start to decrease again, reaching a global minimum from 2015 onwards (see Fig. 2(a)). This reduction is caused by a sharp decrease in sectoral TFP volatilities (see Fig. 2(b), upper panel), while the intermediate input intensity remained roughly constant (see Fig. 2(b), lower panel).

The amplification effect of asymmetries displayed an increasing trend between 2006 and 2009, and a decreasing trend from 2015 onwards. These movements were mainly due to variations in the Cov term (see Fig. 3).

At the sectoral level, about $60 \%$ of the overall reduction in (fundamental) aggregate volatility came from the joint impact of Non-Depository financial institutions, Real estate, Wholesale trade 


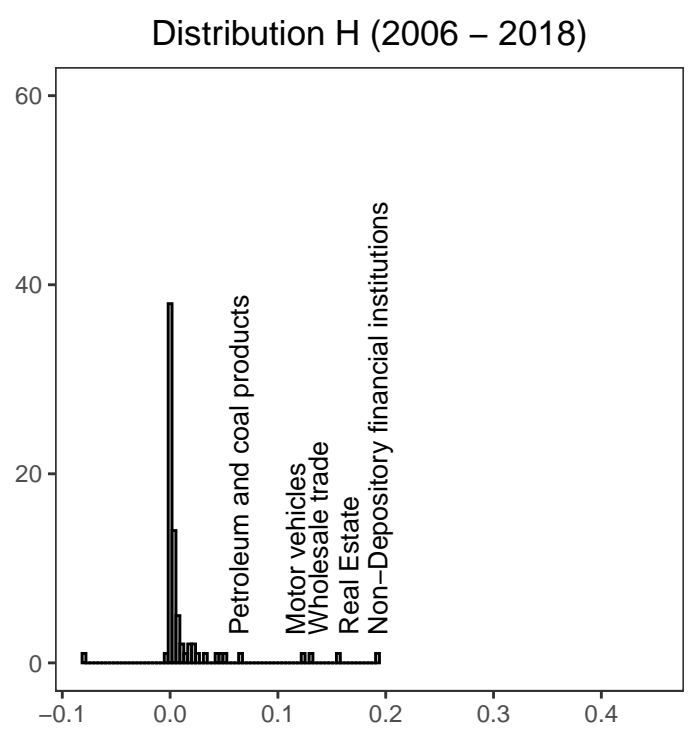

(a)

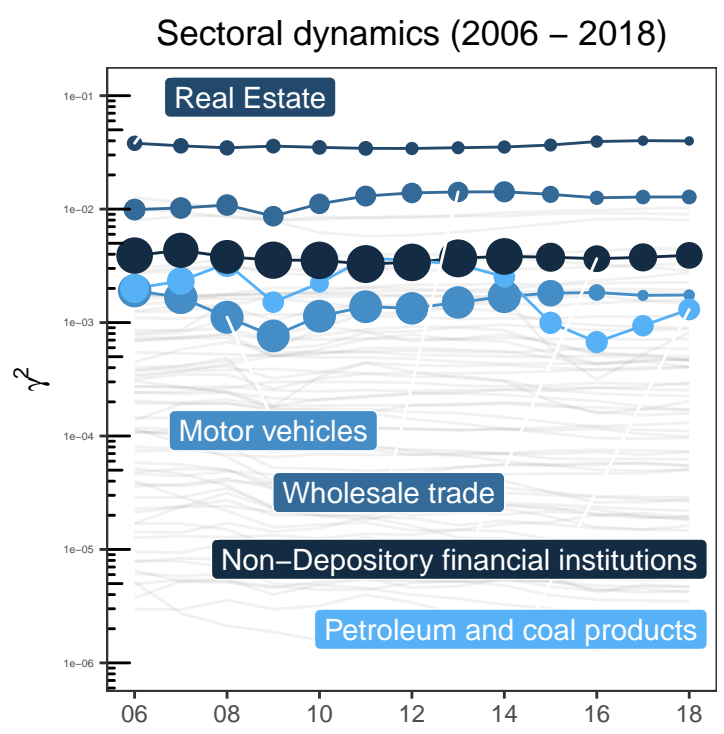

(b)

Figure 8: Panel (a): Distribution of $H_{i}(2006,2018)$. Labels show the 5 most relevant sectors. Panel (b): Time variation of $\gamma_{i}^{2}$ (in $\log _{10}$ scale) for first 5 sectors ranked according to measure $H_{i}(2006,2018)$. Darker to lighter color reflects decreasing sector importance according to $H_{i}$. Circle size is proportional to $\sigma_{i}^{2}$.

and Motor vehicles. All these sectors display a decrease in their TFP volatility and roughly constant Domar weights, confirming the finding that the main driver for the reduction in GDP volatility in the 2006-2018 period has been the decline in sectoral TFP volatilities. An additional $7 \%$ of the volatility reduction is due to sector Petroleum and coal products, while the Insurance sector displayed a strong increase in volatility, thus a negative $\mathrm{H}$, and partially compensated the overall reduction in volatility (see Fig. 8(a)).

\section{Conclusions}

This paper highlights the importance of the interaction between the structure of the production network and sectoral volatilities in determining GDP volatility. We show that sectoral TFP volatilities are important sources of GDP fluctuations. Sectoral volatilities are transmitted at the aggregate level and amplified through the network of production linkages. The amplification effect depends on two factors. First, the intermediate goods intensity of the production system, measured as average gross nominal production over GDP. Second, the asymmetry of the production structure 
determined by the distribution of share of intermediate goods in final good production $\beta$ and the topology of the input-output network $W$.

We explain the rise and fall of aggregate volatility observed during the years between 1966-1994 and 1995-2018 as the combination of three factors. First, an increase and subsequent decrease in average sectoral TFP volatility. Second, a concurrent rise and fall of the intermediate input intensity of the production structure. Third, the change over time of the impact of asymmetry on the transmission of sectoral shocks. We observed that asymmetry had both an amplifying and a dampening effect on aggregate volatility. In fact, although the literature typically associates asymmetric production networks to stronger amplification of micro-level volatility, we find that the actual effect depends on the correlation between the vectors of Domar weights and idiosyncratic volatilities. We find that this correlation is negative throughout our sample, implying that on average sectors with higher Domar weights are associated to lower volatilities. Peaks in aggregate volatility are associated to an higher correlation (less negative) and thus to a stronger amplifying effect of asymmetry.

Finally, our results suggest that the "great moderation" is not dead and that the bump in volatility observed around the 2007 global financial crisis has mainly been caused by dynamics in the Finance macro-industry, whose relative importance for aggregate fluctuations has increased from mid-1990s onwards.

\section{Acknowledgements}

We thank the editor Vincenzo Quadrini and an anonymous reviewer for detailed comments and suggestions. We also thank Mikhail Anufriev, Henrique Cabral, Fabrice Collard, Domenico Delli Gatti and Valentyn Panchenko for helpful comments and stimulating discussions. Non of the above are responsible for errors in this paper. 


\section{References}

Acemoglu, D., Carvalho, V. M., Ozdaglar, A., and Tahbaz-Salehi, A. (2012). The network origins of aggregate fluctuations. Econometrica, 80(5):1977-2016.

Blanchard, O. and Simon, J. (2001). The long and large decline in u.s. output volatility. Brookings Papers on Economic Activity, 32(1):135-174.

Carvalho, V. and Gabaix, X. (2013). The great diversification and its undoing. American Economic Review, 103(5):1697-1727.

Charles, A., Darn, O., and Ferrara, L. (2018). Does the great recession imply the end of the great moderation? international evidence. Economic Inquiry, 56(2):745-760.

Clarida, R., Galí, J., and Gertler, M. (2000). Monetary policy rules and macroeconomic stability: Evidence and some theory*. The Quarterly Journal of Economics, 115(1):147-180.

Cooper, R. W. and Haltiwanger, J. C. (2006). On the Nature of Capital Adjustment Costs. The Review of Economic Studies, 73(3):611-633.

Di Giovanni, J., Levchenko, A. A., and Mejean, I. (2014). Firms, Destinations, and Aggregate Fluctuations. Econometrica, 82(4):1303-1340.

Domar, E. D. (1961). On the Measurement of Technological Change. Economic Journal, 71(284):709-29.

Dupor, B. (1999). Aggregation and irrelevance in multi-sector models. Journal of Monetary Economics, 43(2):391-409.

Gabaix, X. (2011). The granular origins of aggregate fluctuations. Econometrica, 79(3):733-772.

Gadea, M. D., Gómez-Loscos, A., and Pérez-Quirós, G. (2018). Great moderation and great recession: From plain sailing to stormy seas? International Economic Review, 59(4):2297-2321.

Galí, J. and Gambetti, L. (2009). On the sources of the great moderation. American Economic Journal: Macroeconomics, 1(1):26-57. 
Horvath, M. (1998). Cyclicality and sectoral linkages: Aggregate fluctuations from independent sectoral shocks. Review of Economic Dynamics, 1(4):781-808.

Horvath, M. (2000). Sectoral shocks and aggregate fluctuations. Journal of Monetary Economics, (45):69-106.

Jaimovich, N. and Siu, H. E. (2009). The young, the old, and the restless: Demographics and business cycle volatility. American Economic Review, 99(3):804-26.

Jones, C. I. (2011). Misallocation, Economic Growth, and Input-Output Economics. NBER Working Papers 16742, National Bureau of Economic Research, Inc.

Jorgenson, D. W., Gollop, F., and Fraumeni, B. (1987). Productivity and U.S. Economic Growth. Harvard University Press. Reprinted- Universe, 1999.

Jorgenson, D. W., Mun S., H., and Stiroh, K. J. (2005). Productivity, Volume 3. Information Technology and the American Growth Resurgence. MIT Press, Cambridge, MA.

Justiniano, A. and Primiceri, G. E. (2008). The time-varying volatility of macroeconomic fluctuations. American Economic Review, 98(3):604-41.

Kahn, J. A., McConnell, M. M., and Perez-Quiros, G. (2002). On the causes of the increased stability of the U.S. economy. Economic Policy Review, (May):183-202.

Long, J. B. and Plosser, C. (1983). Real business cycles. Journal of Political Economy, 91(1):39-69.

Lucas, R. E. (1977). Understanding business cycles. Carnegie-Rochester Conference Series on Public Policy, 5(1):7-29.

McConnell, M. M. and Perez-Quiros, G. (2000). Output fluctuations in the united states: What has changed since the early 1980's? American Economic Review, 90(5):1464-1476.

Moro, A. (2012). The structural transformation between manufacturing and services and the decline in the us gdp volatility. Review of Economic Dynamics, 15(3):402 - 415.

Stock, J. H. and Watson, M. W. (2002). Has the business cycle changed and why? Working Paper 9127, National Bureau of Economic Research. 
Stock, J. H. and Watson, M. W. (2017). Twenty years of time series econometrics in ten pictures. Journal of Economic Perspectives, 31(2):59-86.

Taylor, J. B. (2011). Macroeconomic lessons from the great deviation. NBER macroeconomics annual, 25(1):387-395. 